\title{
Environmental Control of Root System Biology
}

\section{Rubén Rellán-Álvarez ${ }^{1 *}$, Guillaume Lobet $^{2 *}$ and José R. Dinneny ${ }^{3}$}

${ }^{1}$ Laboratorio Nacional de Genómica para la Biodiversidad (Langebio), Unidad de Genómica Avanzada, Centro de Investigación y de Estudios Avanzados del Instituto Politécnico Nacional (CINVESTAV-IPN. Irapuato, Guanajuato 36821, Mexico; email: rrellan@langebio.cinvestav.mx

${ }^{2}$ PhytoSYSTEMS, University of Liège, Liège, Belgium. Place du 20 Août 7, 4000 Liège, Belgium; email: guillaume.lobet@ulg.ac.be

3 Department of Plant Biology, Carnegie Institution for Science, Stanford,

California 94305; email: jdinneny@carnegiescience.edu

* These two authors contributed equally.

Annual Reviews Plant Biology 2016. $67: 1-26$

This article's doi: $10.1146 /(($ please add article doi $))$

Copyright (c) 2016 by Annual Reviews. All rights reserved

This is an example of dummy text used to illustrate an example of first page note.

\section{Keywords}

root system architecture, root modeling, root environment interactions

\section{Abstract}

The plant root system traverses one of the most complex environments on earth. To understand how roots support plant life on land, we must know how soil properties affect the availability of nutrients and water and how roots manipulate the soil environment to optimize acquisition of these resources. Imaging of soils allows structural features at micro to macro-scales to be analyzed and modeled. Phenotyping root systems has increased in sophistication and is driving innovation in cross-platform compatible methods for data analysis. Root systems acclimate to the environmental through architectural changes that act at the root-type level as well as histological changes that affect the metabolic needs of the root and the efficiency of nutrient uptake. A molecular understanding of the signaling mechanisms that guide local and systemic signaling is providing insight into the regulatory logic for environmental responses and has identified points where cross talk between pathways occurs. 


\section{Contents}

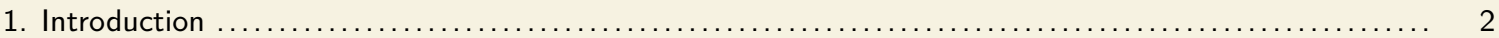

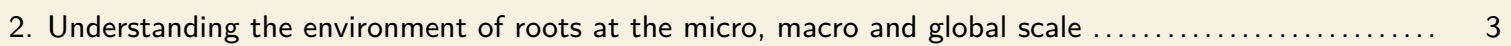

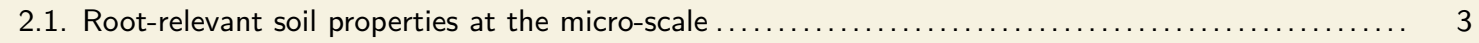

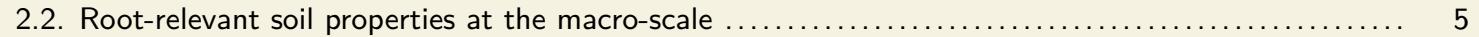

3. Methods for capturing the multidimensional nature of roots through metrics and models $\ldots \ldots \ldots \ldots \ldots .7$

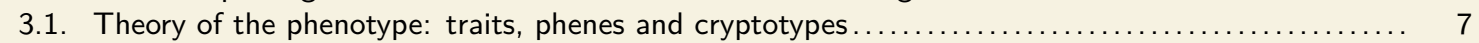

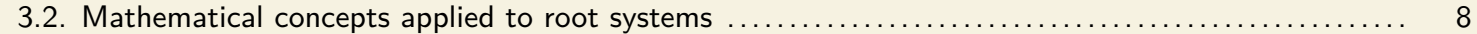

3.3. Root System Markup Language: towards a cross-platform descriptive language for roots. ......... 10

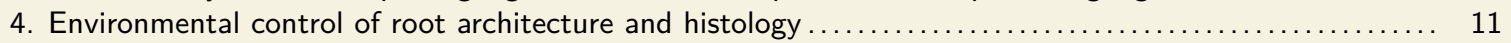

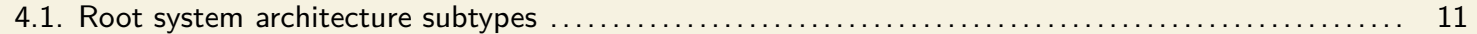

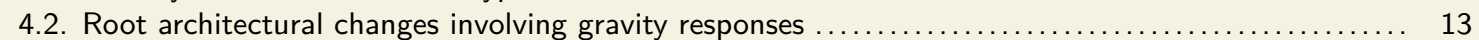

4.3. Architectural changes in response to stress through root-type specific growth control ............ 14

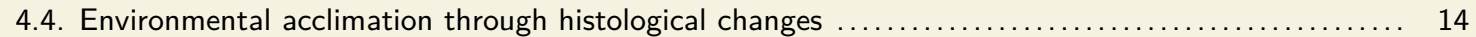

4.5. Hydropatterning may optimize root architecture and histology for efficient water uptake ......... 15

5. Environmental signal integration at the root system and whole-plant level $\ldots \ldots \ldots \ldots \ldots \ldots \ldots \ldots \ldots . \ldots \ldots$

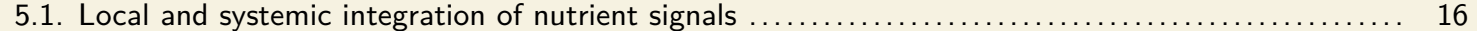

5.2. Towards an understanding of how root systems integrate complex nutritional signals ........... 18

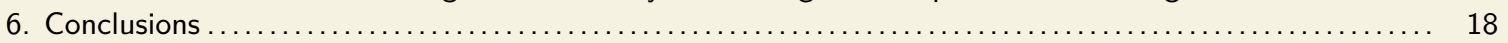

\section{Contents}

\section{Introduction}

The atmosphere and soil meet at the horizon, but it is the plant that bridges these two domains of our planet. The evolution of photosynthesis, first in bacteria, then through adoption of endosymbionts in early plants, transformed the atmosphere by capturing carbon dioxide and generating oxygen (54). However, it was not until plants developed the ability to survive on land during the Devonian period 360-400 million years ago that the second transformation, of the soil itself, began in earnest $(5,10)$. Rhizoids, and then roots, infiltrated the virgin soils on land and changed their physicochemical properties and capacity to maintain life $(116,60)$. With the invasion of plants onto land, the soil and atmosphere became more intimately connected. Through the activity of roots, plants direct the redistribution of water from the soil, through the shoot, to the atmosphere and significantly affect the flux of water in the hydrological cycle (56). In the converse direction, carbon dioxide is chemically fixed through photosynthesis in shoots and sent down into the soil where microbial activity and root-derived metabolites generate organization at the micro- and macro-scales that help make soil the leading store of carbon on the planet $(113,15)$. Thus, the root system represents an important interface through which plants act on, and are acted upon, by the environment with local and global implications.

Root systems are complex physical networks and, as a consequence of this intricate form, have inspired work in the area of systems biology to determine the various molecular components that determine the form of this network (8). Form, however, is not the only property of this system that defines function. Roots provide conduits for the uptake of 
nutrients and water and alter the rhizosphere through the exudation of various metabolites (140). These functions are spatially and temporally differentiated in the root, though our understanding of this aspect is very poor (89). The environment that surrounds plants is as complex as the plant itself, if not more so. The interface between the environment and plants is multifaceted with temporally and spatially dynamic processes affecting the signals that cells perceive (89). Research in the molecular biology of plant-environment interactions has often assumed a simple interaction where changes in a single environmental variable are perceived by the plant in isolation. This approach is largely driven by the use of experimental systems where a single variable can be altered with precision (139). However, changing a variable in a plants environment may also have wide-ranging effects, only some of which are anticipated. Even a simple media such as agar can interact with the plant in complex ways. Work from the Dinneny lab has shown that roots growing on the surface of an agar media experience two remarkably different environments across the circumferential axis (3) and elicits bias in the patterning of root tissues (fig. 1A-C). This spatial acuity in a roots response to the local environment mirrors the scale at which such stimuli vary in soil.

In this review, we define aspects of the multidimensional biology of root systems and establish a framework that may help guide future studies aimed at developing a holistic understanding of root-environment interactions. We first describe the nature of the soil environment and how important properties of the soil vary at micro, macro and global scales. We then discuss the architectural properties of root systems and how mathematical and computational approaches to modeling root systems is enabling a systems-level understanding of the functional properties of these organs. Finally, we define the biological context in which root-environment interactions act with an overview of the root types, tissues and molecular pathways involved in controlling root growth and environmental responses to nutrients and salinity.

\section{Understanding the environment of roots at the micro, macro and global scale}

\subsection{Root-relevant soil properties at the micro-scale}

Many properties of a soil that impact the growth and physiology of roots have their origins in the microscopic details of soil structure (15). Soils are generally classified based on their relative proportion of sand, silt and clay. An important feature of these components is their particle size, which determines the pore space between particles. Soils with smaller particles have less pore space and bind water more tightly due to capillary forces. This effect is quantified by the soil matric potential, which is affected by compaction and drying. Sandy soils allow water to flow readily but dry more quickly compared to clayey soils, which have higher capillarity. As a consequence, while root systems are generally able to extract water more easily from sandy soils, they may suffer more from water deficit as the soil dries and the channels available for water movement become filled with air.

Strong heterogeneity in soil conductance can arise in the immediate environment of the roots, modifying the path of least resistance for water flow. Water uptake sites will shift from the dry to the wet portion of the root system, leading to what is termed a compensatory uptake mechanism $(58,127)$. Thus, uptake dynamics are not driven solely by plant hydraulic architecture, but are also strongly influenced by the soil properties (27). An extreme example of this compensatory mechanism occurs when roots undergo a 
Macropore: Channel formed in soil through the activity of roots or animals that facilitate water and air flow as well as new root growth.

Rhizosheath: Regions of roots that tightly bind soil and form specialized microenvironments thanks to root exudates and mucilage process known as hydraulic lift in which water can flow out of the root into soil at night when root pressure is high (19). This has been proposed to be important for enabling root growth in dry regions of soil and for aiding in nutrient uptake.

At a higher spatial scale, structural features such as cracks and macropores affect soil properties $(89,97)$. Wetting and drying cycles in soil cause swelling and shrinking, respectively, which induce cracks that can extend deep into the soil. Macropores are small channels in the range of 30 microns to $3 \mathrm{~mm}$ and can vary in length, width and tortuosity (fig. 1A, B). Macropores are also generated by animals such as earthworms or roots themselves and are important avenues for root growth. Their effect on roots is in part a consequence of the lower resistance they provide for growth and movement of air and water. In addition to macropores, roots affect the structure of soil through the formation of rhizosheaths, which are regions of roots that tightly bind soil and form specialized microenvironments (143) (fig. 1D, E). Rhizosheath structure is dependent on root mucilage (140), which are complex polysaccharides exuded by the root cap that form hydrated gels (hydrogels) and bind soil particles (143). These exudates may affect the colonization of the root by microorganisms, which themselves contribute to the complex composition of rhizosheath organic matter. Rhizosheaths in maize form proximal to the root tip in regions where xylem maturation has not yet been completed and water uptake is limited $(143,96,90)$. The relationship between water availability and rhizosheath formation was identified by Watt et al. who measured parameters of this structure in roots exposed to local water deficit. Interestingly, the diameter of rhizosheaths and their structural integrity are highest in regions of soil with lower water availability suggesting that rhizosheaths may be important under drought. Indeed, work by North and Park found that root segments of cactus with rhizosheath formation maintained contact with soil particles better than parts of the root that did not (96).

Rhizosheaths tend to be absent from more mature regions of the root. In maize, this corresponds to where water uptake is likely highest (90). The rhizosheath may act as a domain that facilitates several processes that must coordinately occur for effective nutrient uptake including: hydration of soil particles, contact of the root with the soil and, perhaps, enhanced microbial activity due to the prevalence of exuded fixed carbon (66). Thus the rhizosheath represents a structure dependent on both the root and soil systems with developmental and environmental parameters determining the nature of the rhizosheath as well as its likely function. What genetic pathways are responsible for the formation of rhizosheaths and whether selection for germplasm with improved rhizosheath formation would benefit root system efficiency is unknown.

X-ray micro-Computed Tomography (microCT) and magnetic resonance imaging (MRI) are being applied to study the architecture of root systems in natural soils and enable microscopic features of soil to be measured (92). The development of computer vision algorithms for semi-automated extraction of root architecture provides the opportunity to study root growth in natural field soil (86). While not frequently applied together with quantification of root growth, microCT has been used to characterize soil structure and the effects of compaction on pore space (134). Tremendous opportunities exist for finescale quantification of water, air, soil particles and root, however algorithms must also be developed for characterizing the function of soils based on these data. Models of soil 
chemical and physical properties (matric potential, hydraulic conductance, hardness) need to be designed that enable prediction of such properties based on image data (135). These data can be integrated into plant-physiological models such as SimRoot to predict the effects of the soil environment on root physiology (109).

\subsection{Root-relevant soil properties at the macro-scale}

The architecture of roots is of general importance because the distribution of nutrients and water is not uniform in soil at the macro-scale (84). Thus, the position of roots within the soil column will determine, in part, the efficiency with which a root system captures these valuable resources. The distribution of water is generally determined by gravity, however, porosity of soil, the presence of hard pans and macropores will influence the rate of bulk flow (15). Some nutrients such as nitrogen follow similar principles as water as they do not bind tightly to clay particles in soil. Phosphorus, on the other hand, is generally present at very low levels in soils and in chemical forms that are unavailable to the plant. Decomposition of organic litter in the top soil typically leads to higher levels of phosphorus in these upper tiers. Inorganic phosphorus moves slowly through soil as it binds to clay, iron and aluminum oxides. Root proliferation in regions of soil with higher phosphorus and the production of root hairs promotes uptake of this resource (84). In addition, acidification of the soil through the action of proton-ATPases mobilize phosphorus and increase its availability to the root (144).

Due to the varying distribution of nutrients and water, root systems that are optimized to take advantage of one resource may be suboptimal for others. Work by Postma and Lynch have utilized the SimRoot mathematical model to simulate the functions of root systems with varying density and lengths of lateral roots (109). Root systems optimized for nitrogen uptake had longer and more sparsely spaced lateral roots while root systems optimized for phosphorus uptake had more densely spaced and shorter lateral roots. An important finding of this work is that high local lateral root system density may become disadvantageous if resources are highly mobile and lateral roots compete with one another for nutrients. These computationally derived root architecture ideotypes inform breeding efforts to identify genotypes best suited for particular agricultural lands. Importantly, however, the potential tradeoff of optimizing root systems for particular nutrient stresses is not clear in the field. Plasticity in root architecture traits as a consequence of environmental stress has been described but has not been well investigated as a trait in itself. Is it possible to select for certain architectural responses to nutrient deficiencies and stress rather than static ideotypes? How much variation in nutrient uptake exists in species independent of root architecture? Do developmental and physiological differences between root types and developmental stages constitute an untapped source of phenotypic variation in root function?

Soil constituents can also have negative effects on plant growth. Salinity affects soils throughout the globe, most prevalently in arid regions of Australia, Africa, Latin America and the Near and Middle East (15). Salinity is caused by the accumulation of solutes that arise from the weathering of minerals as well as fossil deposits. Salts are dissolved in all supplies of water and usually become deposited in low-lying flat land as a result of water flow from higher elevations. Groundwater may also be a source of salinity with rising 

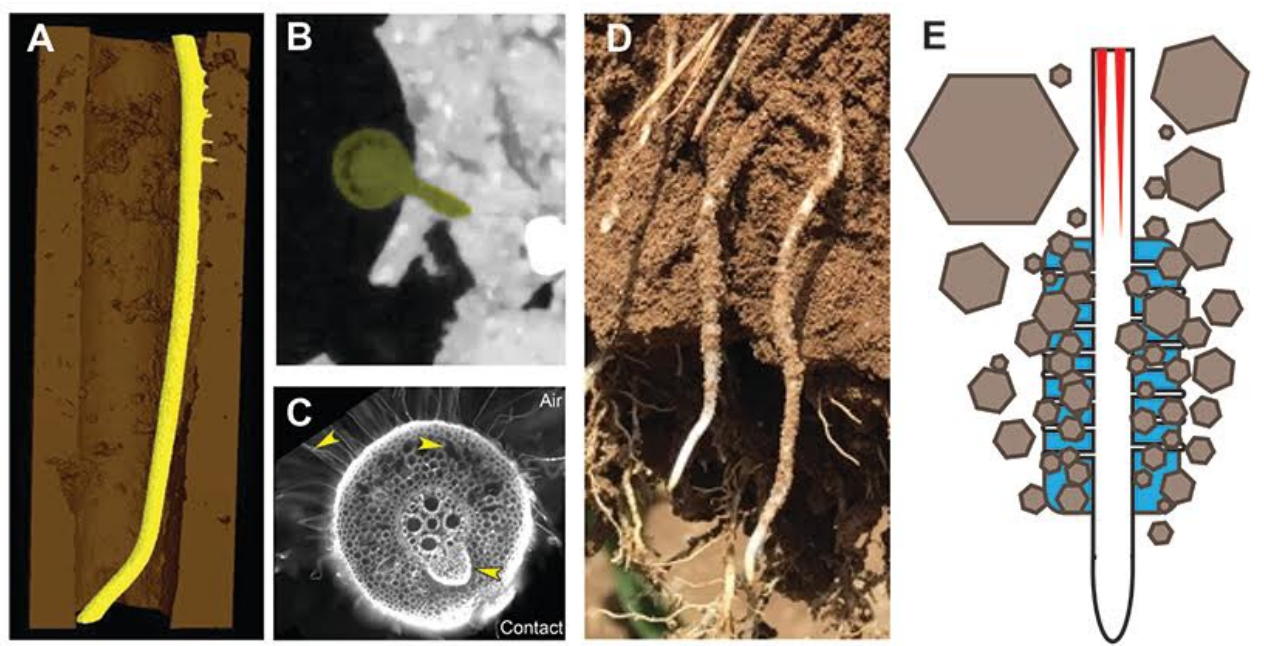

Figure 1

The biology of roots in soil. (A) X-ray microCT 3D rendered image of a maize root (yellow) growing through a macropore of field soil (brown). Note the development of lateral roots on the side of the primary root contacting the soil (images in A, B courtesy of Craig Sturrock and Sacha Mooney, Hounsfield Facility, University of Nottingham). (B) Cross-section from root in (A) showing the development of a lateral root towards the contact side and air pockets (dark region) termed aerenchyma in the cortical tissues of the air-side. (C) Brightfield image of maize root cross section showing aerenchyma development on the air side and lateral root initiation on the contact side (image courtesy of Neil E. Robbins II, Stanford University). (D) Shovelomics-excavated root crown of maize showing nodal roots with rhizosheath surrounding the root. (E) Diagrammatic representation of the rhizosheath. Soil particles adhere to a matrix of mucilage (blue) and root hairs. Red stripes indicate region of root where mature xylem cells enable rapid water uptake and correlates with loss of rhizosheath integrity.

levels bringing solutes to the surface of soil through capillary action and evapotranspiration. Because no source of water used in agriculture is without dissolved salts, irrigation often leads to salinization if drainage is not properly controlled. Indeed, history provides strong examples of civilizations where salinization led to agricultural disaster. The farmers in the Fertile Crescent of the 12th century utilized irrigation to increase productivity while drainage was insufficient to remove accumulated salts (15). As a consequence, large swaths of land in southeastern Iraq became abandoned, and are still useless for cultivating crops today. More recently, an estimated $10 \%$ of agricultural land is abandoned each year due to salinity, which is similar to the amount of land brought under cultivation through the introduction of irrigation (39).

Salinity is also influenced by proximity to the coast, with sea spray and the influx of seawater onto land being important contributors $(78,15)$. Natural variation in the salt tolerance of Arabidopsis was shown to correlate to proximity to the coast and this work led to the identification of a specific allele of the sodium/proton antiporter HKT1;1 as a determinant for this phenotypic variation (6). More recently, common garden experiments have shown that Arabidopsis accessions that were collected close to the coast are generally more fit when grown close to the coast while inland accessions show reduced fitness when grown at the coast (17). 
At a smaller spatial scale, salinity can vary with soil depth in complex ways, with higher concentrations occurring deeper in the soil column as a consequence of groundwater stores, and can be high at the surface layers as well due to seepage and evaporation $(146,15)$. It will be interesting to determine how the structure of the root system may contribute to differences in salt tolerance and whether root architecture ideotypes exist that provide advantages in saline environments as they do for nutrients (61).

\section{Methods for capturing the multidimensional nature of roots through metrics and models}

Environmental conditions affect the structure and physiology of the root system in complex ways and understanding this process requires quantification and classification schemes that capture the multidimensional properties of the system. As a consequence of recent advances in root phenotyping, it is particularly timely to carefully consider the theoretical nature of the phenotypes we assay and the strategies used for capturing and sharing such data. These approaches affect the way we communicate the results of our experiments and also impact our ability to model such phenomenon using quantitative approaches.

\subsection{Theory of the phenotype: traits, phenes and cryptotypes}

Root system complexity calls for multiple phenotyping strategies of varying granularity. Global traits, such as rooting depth and width, total root surface or convex hull area, are simple yet effective ways to quantify root systems. They usually summarize the general shape and exploration efficiency of the root system in a few metrics. These can be computed automatically from root images (e.g. with GiA Roots (41)), and have been used frequently in quantitative genetic studies $(133,147,36,128)$. However, one drawback of using global traits is that they are often the result of a combination of several other, more fundamental, traits. For instance, root system width is influenced by the lateral root gravitropic setpoint angle (see fig. 3), changes in lateral root gravitropism and/or lateral root growth. Therefore, looking for a precise genetic basis for root system width is likely to be difficult. For this reason, Lynch and co-workers recently proposed that quantification of root traits should focus on phenes, which are fundamental components of the phenotype $(145,82,80)$. Phenes are defined as the smallest quantifiable phenotypic elements, that can not be divided further. While the definition of a phene is conceptually simple, its practical application is not always straightforward. The gravity response of a root could be seen as a phene, since it can not be defined by any other macroscopic variable. However, plant phenomics are not restricted to measurement of only the physical properties of an organism and can also encompass its chemical composition (40,85). Thus, since gravitropism has been shown to be influenced by the expression level of several genes, such as $A U X I N$ RESISTANT 1 (AUX1) (9) or PIN-FORMED (PIN) (121), the expression levels (the mRNA composition) themselves could then be seen as phenes.

Depending on the scale considered, the plant physiological age, the resolution of the measurement method used or the questions at hand, different phenes might then be considered and measured. It can then be postulated that the phenotype is, by definition, infinite $(21,85)$. Despite recent and future technical advances, the measured phenotype 
Phene: Building block of the phenotype. Unique and indivisible in any other phene.

Holophenotype: The complete, infinite, plant phenotype.

Cryptotype: The set of phenes that separates the best $a$ priori classes.

will always remain a subset of the complete plant phenotype, or holophenotype (21). In line with this observation, Chitwood and Topp proposed to introduce the concept of cryptotype (crypto standing for hidden, as opposed to pheno, standing for show). They defined the cryptotype as the set of traits (multivariate phenotype) that separates classes (genotypes, treatment, time points) chosen a priori. The cryptotype is therefore unknown, hidden, until the experiment reveals it. Again, the cryptotype is subjective by definition, and strongly depends on the investigated question and the methods used to interrogate the system. In the end, we will aid our understanding of root function if our studies focus on characterizing processes that directly affect root physiology, rather than through indirect proxies ; the most useful terminology should aid in understanding functional connections in biological systems.

Phenotyping exercises often fail to explicitly measure local environmental conditions and instead focus on plant traits aggregated at the organism scale. This is particularly true of root systems, for which even a subset of the roots might be sufficient to retrieve statistically meaningful information (e.g. root diameter classes) (35). However, aggregating metrics at the organism level partially hide how individual roots respond to their local environment. Since the soil environment may change dramatically during the lifetime of the plant , intrinsic root plasticity can be an important feature for plant survival $(106,81)$. To understand the mechanisms underlying plasticity, we need to measure attributes of the root system in both space and time, to build quantitative response curves. From these response curves, a selected number of parameters can be extracted (e.g. the slope and intercept) for which genetic determinism can be found. This approach is already used to quantify cavitation in xylem vessels (136), but has been seldom applied to roots. A similar methodology was successfully applied with ROOT-FIT (61). The authors were interested in root response to different levels of salt stress. Instead of comparing the root length at different time points, they synthesize the measurement in one quadratic root growth curve parameters for each plant. Although these curves did not directly incorporate environmental conditions, this example shows that more integrative metrics can be obtained.

The way we represent root systems and their environment has a strong influence on how we consider the whole system. Reducing the root system to a few metrics conceals its innermost complexity. Similarly, excluding the environment from the analysis leaves half of the reality out of the picture. While these simplifications were (and are still) often necessary, todays technical advances calls for a more complete and integrative way of representating the soil-root system.

\subsection{Mathematical concepts applied to root systems}

3.2.1. Root systems as trees. From a mathematical point of view, root systems are trees. The entire system is indeed organized as a binary hierarchical structure, formed of nodes (branching points), branches (connections between two branches) and leaves (terminal branches). Root system topology is physiologically relevant, as it determines preferential fluxes (of water, nutrient and sugars) between the different organs of the plant. In the late 1980's, Fitter proposed simple topological metrics for the analysis of root systems (37). They were designed to provide a collection of topological descriptors able to discriminate species, genotypes and treatments. Although some of these descriptors were shown to be correlated with more classical variables, such as root exploration 
(38), they are seldom useful in root research. This is due to two major bottlenecks. Firstly, complete topology is often difficult to acquire, especially at high-throughput (74). Secondly, topology can be seen as the result of several traits, such as lateral root branching density, maximal branching order or root growth rate and other individual metrics. These individual metrics have often been preferred to topological ones since they are more directly related to the developmental processes leading to the emergent topological features.

Nevertheless, topological representation has been used for decades in root models $(79,49)$, as it is the most natural way of representing root systems (both from a mathematical and biological point of view). Current models can be broadly divided in two main groups. First, models describing the root system architecture alone have been used to understand the building mechanisms of the root networks $(79,49,104,103,72)$. Second, functional-structural plant models (FSPM's) have been created to explore the cross-talk between root systems and their soil environment (for a review on the currently developed models, see (30)). As with the first group of models, FSPMs represent the whole root architecture explicitly. In addition, each element of the root system can interact with its exogenous (e.g. the soil) and endogenous (e.g. the neighboring roots) environment. These models are often coupled with soil models to simulate realistic environmental conditions (47) and allow researchers to test hypotheses in silico before testing them experimentally.

FSPMs can be used to dissect processes that can not be easily separated in vivo, in order to investigate their individual contributions. For instance, SimRoot (83) has been extensively used to analyse which root system architecture traits have the most important effect on phosphorus and nitrogen uptake and whole plant physiology. By varying individual root traits, Lynch and co-workers showed the large influence of root gravitropism (43), root insertion angle (52), root cortical aerenchyma $(110,111)$ or lateral root density (109) on these processes. Complex, multi-layered processes, such as root water uptake dynamics are also effectively studied with FSPMs. R-SWMS is a simulation tool that links a model of tridimensional water flow in the soil domain to a root architectural model (59). As of today, it is the only model to explicitly simulate water movement in the whole soil-root domain. It was used to vary specific properties of the soil-plant system to understand their contributions to the overall water uptake process. In particular, the model was used to investigate the effect of root hydraulic architecture (27), soil salinity (125) and long-distance chemical signalling (55) on the root water uptake dynamics. The model also highlighted the predominant influence of the soil on the water uptake dynamics in drying soil (27).

The major bottleneck in the use of FSPMs remains the lack of quantitative datasets to parameterize such models. While most physiological studies are based on qualitative data, very few have produced quantitative measurements that can be directly used in modelling platforms. Response curves on how the different processes change with the plants environment are needed.

3.2.2. Root systems as densities. Representing the root system as a tree is not always appropriate. First, a complete topological map of the root system may not be available, or only partially. For plants grown in rhizotrons, for instance, only a fraction of the root system is visible, though this can be improved substantially with expression of reporter
Graph: Set of connected objects

Tree: Mathematical trees are a subset of graphs. They are directional (parent/child relationship) and acyclic

FSPM: FunctionalStructural Plant Model, linking an explicit representation of the plant architecture with physiological processes (uptake, production, transport)

Rhizotron: Flat container, with at least one transparent side used to grow plant. Root grow is recorded on the transparent side(s) 
XML: eXtended Markup Language. Hierarchical markup text format.

genes such as luciferase (115). Secondly, root systems at late stages of development might be too complex to be analysed topologically (115). Finally, from a simulation point of view, explicit models of mature root system can become highly demanding in terms of computational resources needed (32). In these cases, representing the root system as a set of distribution functions (32) may be more convenient. These functions can represent the distribution of root branches (31), root meristems or even root orientations $(33,115)$. Such models were shown to be able to reconstruct realistic root architectures from simplified datasets. In addition, such methods summarize the different root properties by soil volume units (31), making it more closely related to the representation of a 3D soil structure (32). This opens the door to more efficient soil-root interaction models, that can be used on a larger scale (e.g. field) than typical functional-structural models.

\subsection{Root System Markup Language: towards a cross-platform descriptive language for roots.}

The past few years have seen an increase in the number of tools for the characterisation of root system architecture. These tools range from the design of root phenotyping setups $(71,88,115,26)$, to the extraction of root information from digital images $(130,18,115)$, the analysis of root architecture data $(61,12)$ or the modeling of root processes $(72,75,20)$. The advent of so many tools reflects the fact that none of them is universal. Instead of one single tool, the root research community has adopted a diverse toolbox, each of its elements matching a specific need based on the imaging modality used and the complexity of the root system analyzed. But, as for any toolbox, a minimal level of standardisation is required to ensure cross-compatibility between different tools and the data sets generated.

Recently, the Root System Markup Language (RSML) was proposed as a standard format to store any type of root architecture data (76). Based on the XML formalism, the RSML format was designed to store three levels of information (graphically represented in fig. 2). First, the structure of the file (the relative placement of the different elements) reflects the topology of the root system. Second, each root is individually defined by its geometry (a polyline describing the position of the root in space). Finally, different functions can be superposed on top of the geometry, describing any local properties (root diameter, root orientation, soil water content, etc.). Used in combination with a multidimensional phenotyping platform, such as GLO-Roots (115), RSML files can also be used to store local gene expression information (fig. 2B). Explicit links between the different functions (they are all mapped on the same root morphology) enables the establishment of response curves at the plant level. The modularity of RSML allows the user to either compute response curves directly from the raw data (fig. 2C) or to store the curve parameters in the file for faster meta-analysis.

While the tree like structure of the RSML is ideally suited for the storage of root system information, it is not the best choice for soil information. Indeed, soil elements are not connected as a network, but as a 3D matrix, each voxel being in continuous exchange with its neighbours. Topological links are useless to help understanding the matrix dynamics. So while the information contained in the RSML tells us how the root elements react to changes in their environment, it does not inform us about the influence of the root system on the soil system. To fully understand how the root system development influences the soil 

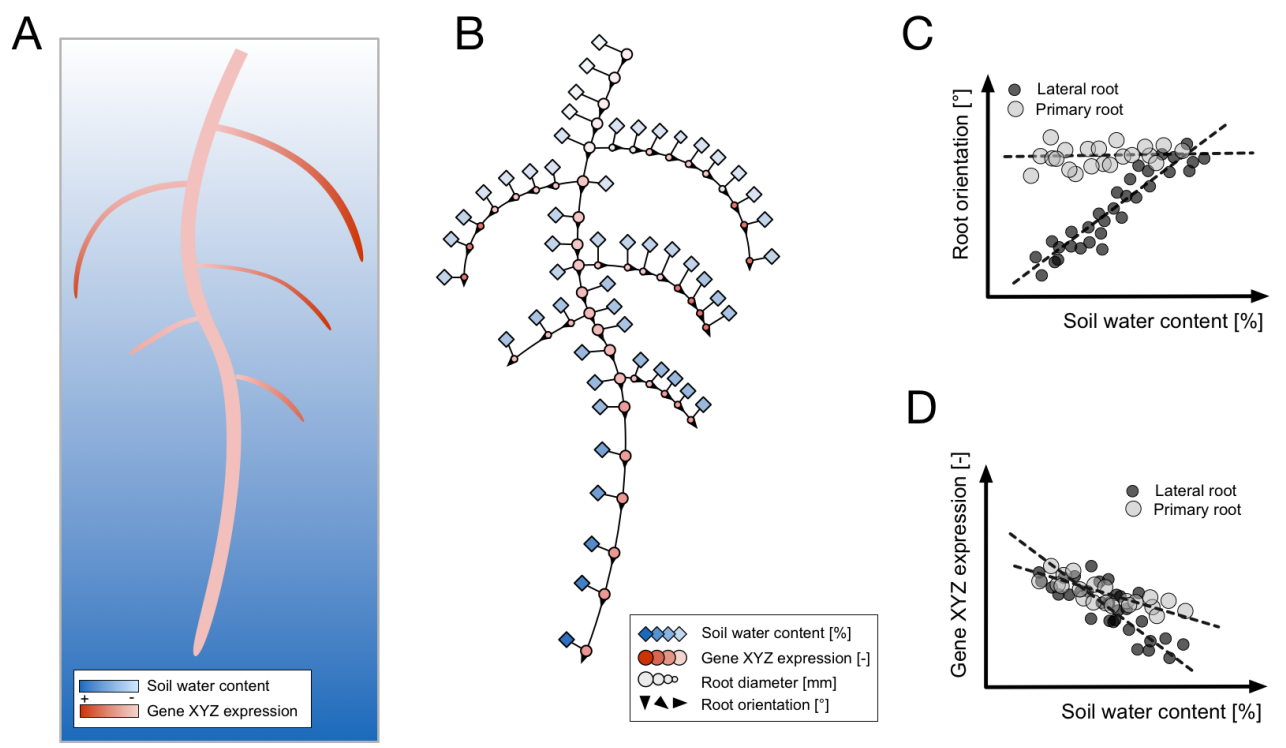

Figure 2

Representation of a root system and its environment A. Schematic representation of a root system growing in soil. Blue level indicates the soil water content (the lighter, the less water). Red level indicates the expression level of an hypothetic gene XYZ. B. Graphical representation of the information stored in the corresponding RSML file. The RSML format enables the storage of the root topology and morphology as well as any local attributes. In this example, the RSML file contains local information about the root diameter, the root orientation, the soil water content and gene expression level. C,D. The rich information contained in the RSML enables the establishment of root response curves to their environment.

processes, it is then necessary to link the experimental data with modelling tools. To do so, experimental data (encoded as a RSML file) can serve as input for compatible modeling platforms (such as R-SWMS (59) or RootBox (72)). The modeling platform enables access to data that are difficult to access experimental (e.g. the actual water flow in the soil domain).

\section{Environmental control of root architecture and histology}

\subsection{Root system architecture subtypes}

Root systems are composed of distinct root types that show characteristic responses to environmental cues and give rise to a physical network with diverse functionality. Root systems can be broadly divided into two types in the angiosperms: i) tap root or allorhizic systems, which are characteristic of eudicot species, and ii) fibrous or homorhizic root systems, which are characteristic of monocots (fig. 3). For reviews describing differences between these root system in detail see: $(101,102,53,122)$. 

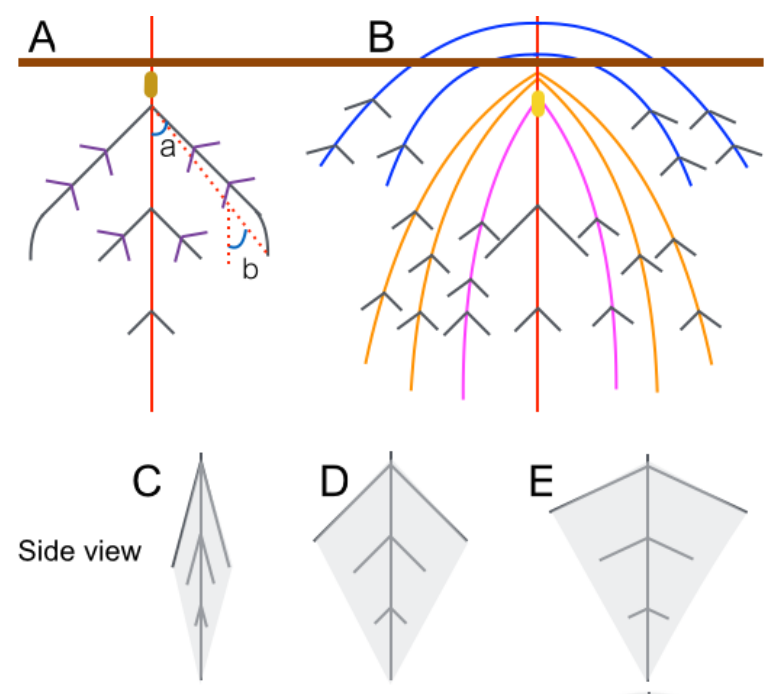

Top view
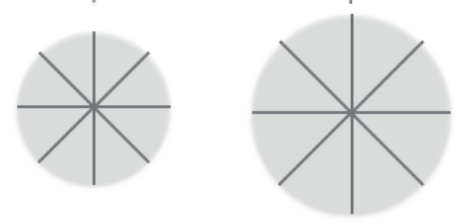

Figure 3

Diagram showing basic root system architecture and different root types of taproot (A) and fibrous (B) root systems. Lateral root gravitropic set point and root tip angles are labeled as (a) and (b), respectively. Primary root types are colored in red, lateral roots in black, seminal roots in magenta, crown roots in orange and brace roots in blue. Side and top view of 3 different root systems with lateral root angles of $15^{\circ}(\mathrm{C}), 45^{\circ}(\mathrm{D})$ and $65^{\circ}(\mathrm{E})$. Potential root foraging area is shaded in gray.

RSA: Root System Architecture. Three dimensional assembly of the different root types that compose the root system

GSA: Gravitropic Setpoint Angle. Angle, relative to the gravity vector, at which an organ (root or shoot) growth is maintaingd as a consequence of gravitropism (22)
Tap root systems (fig. 3A) are composed of a primary (tap) root and lateral roots that emerge from the primary root. The depth of the primary root, the periodicity of lateral root patterning (94), their gravitropic setpoint angle, their growth rate and root tip angles define the potential volume of soil that can be explored and foraged for resources by the root system (fig. 3C-E). All these factors controlling lateral root development are highly plastic and are modulated under different environmental conditions (See below).

Fibrous root systems (fig. 3B) can be divided into embryonic and post-embryonic roots and are typical of grass species. Embryonic roots are divided into primary and seminal roots and emerge from the seeds. Embryonic roots are important during the establishment of the seedling and the early stages of plant development. At later stages, post-embryonic

Rubén Rellán-Álvarez, Guillaume Lobet and José R. Dinneny 
roots take a more prominent role. Post-embryonic roots are divided into shoot-borne roots, which develop from the nodes of the shoot, and lateral roots, which develop from lower-order roots. The regulatory networks controlling the emergence of post-embryonic roots is similar between them and is also shared with Arabidopsis lateral roots (100). Shoot-borne roots that emerge below-ground are known as crown roots and constitute most of the root system biomass in adult plants. Crown roots are organized in different levels of whorls. The number of crown roots, depth and angle is a highly plastic trait that can adjust to different environmental conditions and plays a fundamental role in water and nutrient acquisition (see below). In maize, the Tb1 locus Teosinte branched 1 (Tb1), which was fundamental for the domestication of modern maize from wild teosinte, (25), controls the number of tillers as well as crown roots (42). In some species like maize, brace roots, which emerge from the above-ground part of the shoot, play an important role in providing anchorage and preventing lodging (53). Lateral roots can emerge from any root type.

The root types described above constitute the basic scaffold of root system architecture. However, most of the total root system length is made up of fine roots (secondary and higherorder roots). Due to their small size, fine roots can increase root surface contact with soil and reach into soil micropores defining the effective volume of soil that is actually foraged for nutrients and water. Fine roots also constitute the largest number of root tips in the root system (89).

\subsection{Root architectural changes involving gravity responses}

Root system architecture plasticity is defined as the ability of a root system to adjust its architecture to different physicochemical soil cues. This plasticity is largely based on the different root type developmental programs and unique physiological responses to soil conditions (132). One of the most obvious differences between primary roots and lateral roots is their different sensitivities to gravity. Primary roots are generally more gravitropic and establish the depth at which lateral roots develop $(81,137)$. Variation in the gravitropic set-point angle has been observed between related species. For example, the tomato wild species Solanum pennellii, which originates from dry areas with rare precipitation events, shows a primary root angle of about $60^{\circ}$ while the cultivated variety Solanum lycopersicum var. M82 exhibits an angle of only $10^{\circ}(119)$. Shallow roots may be an adaptation to rapidly capture water from recent precipitation events.

The gravitropic set-point angle of lateral roots is controlled by the auxin pathway. When external auxin is applied, lateral roots become more vertically oriented (121) while pharmacological inhibition of auxin synthesis (121) or genetic knockout of the the auxin receptor TIR1tir1-1 leads to a marked lateral root agravitropic response $(121,115)$.

Recent work by the Dinneny lab has shown that, under simulated drought conditions, lateral roots grow at a steeper angle and this change in gravitropic set-point angle is dependent on auxin perception (115). Interestingly, this process is independent of hydrotropism, which has been shown to direct growth towards regions of soil with higher relative moisture (95). While hydrotropism generally acts in opposition to gravity responses, drought-induced changes in root growth may act by enhancing the gravity response. Loci affecting the auxin pathway may also be important for variation in lateral root gravitropic set-point angle. In 
Soil exploration efficiency: Soil area depletion divided by root area. See (70)

rice, the Deeper Rooting 1 QTL confers higher yield under drought conditions and positively regulates gravitropism (137).

\subsection{Architectural changes in response to stress through root-type specific growth control}

Nutrient bioavailability is a major factor controlling growth dynamics and physiology of different root types. The molecular pathways controlling the effect of phosphorus deficiency on root system architecture has been extensively studied (see $(77,51,46)$ for recent reviews). Root system architecture changes in response to phosphorus deficiency generally lead to a greater root density in the top layers of soil, where phosphorus tends to be released by the degradation of organic matter (70). The strategies used by plants to achieve this higher topsoil exploration vary between species. In Arabidopsis primary roots, growth stops (129) and lateral root growth is stimulated by a modulation in auxin sensitivity dependent on the auxin receptor TIR1 and the auxin response factor ARF19 (107). In bean, varieties with shallow basal root growth angle (93) and, in maize, a higher number of crown roots and associated lateral roots (7) are more efficient at acquiring phosphorus. Highly phosphorus- efficient species such as members of the Fabaceae and the Proteaceae families have developed specialized types of roots that are known as proteoid or cluster roots (68), which form highly dense clusters of lateral roots. Proteoid roots are generally ephemeral but have a high metabolic activity and generate bursts of organic acid exudates and phosphatases Lambers2013Interactions.

Work from the Dinneny lab has shown that responses of primary and lateral roots to salinity is distinguished at the level of growth and hormonal signaling. Live-imaging of Arabidopsis seedlings after transfer to salt stress revealed that both root types show dynamic changes in growth but at very different time scales. While the primary root enters a growth quiescence period for several hours before recovery, lateral roots enter quiescence for days $(45,29)$. The different response in lateral and primary roots was explained by different effects of ABA on growth during salt stress and the timing of such signaling. Interestingly, in both cases, ABA signaling in the endodermal tissue layer was critical for growth control during salt stress, highlighting important functions for this cell layer in regulating growth and sodium uptake under inhospitable conditions $(23,118)$.

\subsection{Environmental acclimation through histological changes}

Radial cellular organization of roots is typified by several layers of concentrically organized specialized tissues (87). The function of these tissues and their organization in the root can change depending on environmental conditions and affect the pathway by which water and nutrients are transported (87). In the last few years, thanks to the development of techniques that allow root cell-type-specific transcriptional profiling and gene activation/knockdown, we have started to understand the developmental programs, hormone signalling, and environmental stimuli unique to the different root cell types $(45,16,24)$.

The epidermis is the first layer of contact with the rhizosphere. Epidermal cells initiate contact with symbiotic bacteria, such as the nitrogen fixing rhizobium, to form an infection thread that transmits the bacteria to inner cell layers (99). The length and density of root hairs also plays roles in determining the efficiency with which phosphorus 
is extracted from soil (93). In some species, an exodermis develops from the outermost cortical cell file and may act as a hydraulic barrier against water loss (117). Further inside, the cortex constitutes one to many cell layers of the root and acts as an important center for metabolism (57) and colonization by fungal endophytes (126). Cortical tissues can also undergo programmed cell death or cell-cell separation processes that lead to air-spaces in a tissue known as aerenchyma. Aerenchyma may promote the ability of oxygen to diffuse into the hypoxic soil environment and facilitate aerobic metabolism. Aerenchyma also enhances root growth under macronutrient deficiency conditions likely due to reduced metabolic costs of this tissue type (124). Since water movement is slow through air, aerenchyma may also provide a hydraulic barrier to water loss (117).

Internal to the cortical layers, the endodermis $(44,118)$, acts as a hydrophobic diffusion barrier that regulates water and nutrient passage, amongst other functions. Endodermal cells develop a Casparian strip made of lignin that limits the diffusion of molecules into the stele. In maize, the radial expansion of the Casparian strip is increased and may enhance the barrier function (62). A similar increase is observed in Arabidopsis and genes associated with Casparian strip formation are transcriptionally induced by salt (45). The integrity of the Casparian strip has recently been shown to be necessary for maintaining nutrient homeostasis (108).

Internal to the endodermis is the pericycle cell layer, which maintains meristematic activity and is the site for the development of lateral root primordia (138). The specification of lateral root founder cells in the pericycle is generally thought to be resistant to environmental control, however, recent discovery of the hydropatterning response (see below), and characterization of the local effects of water deficit, suggests that these early events may be targets of water-associated stimuli $(2,3)$.

At the core of the root, xylem and phloem vessels transport and distribute water and nutrients from the root to the shoot and photoassimilates from the shoot to the root. Plants under nutrient deficiency, upregulate expression of the transporters involved in xylem loading of nutrients (50) or molecules (34) involved in nutrient-long distance transport (114)

\subsection{Hydropatterning may optimize root architecture and histology for efficient water uptake}

The particulate nature of soil and the effects of gravity and evaporation cause microscale spatial variation in the distribution of water and air. The spatial scale at which roots sense such variation was not understood until we published our work defining a novel plant response we termed hydropatterning (3). In Bao et al. we showed that roots of a diverse set of plant species are able to sense the local distribution of available water and use this as a positional cue to pattern root branching and the local differentiation of root hairs and aerenchyma $(1 \mathrm{~A}-\mathrm{C})$. We defined the properties of water that control root branching and showed that hydraulic conductivity is likely the key environmental variable affecting this process. Developmental analysis of root patterning showed that water biases the positioning of founder cells that later form lateral roots and that these responses occur at the root tip. Characterization of the signaling pathways controlling hydropatterning showed that local control of auxin biosynthesis and transport was observed and these 
processes were necessary to transmit patterning information downstream of moisture. Hydropattering illustrates that environmental signaling can affect the development of the root at the sub-organ level to influence organ system-level and histological patterning processes.

\section{Environmental signal integration at the root system and whole-plant level}

Root and shoot growth must be coordinated due to the mutual dependency of these organ systems for the products of photosynthesis and soil-based resources. Systemic signals are an important mechanism by which shoot and root organ systems communicate limitations in the availability of such resources. In this section we highlight recent studies elucidating the molecular mechanisms that communicate and integrate environmental cues at the local and whole-plant level.

LRR-RK: Leucine Rich Repeat Receptor Kinases: Transmembrane proteins that recognize extracellular ligands -like small peptidesactivating and intracellular kinase that triggers downstream signalling pathways

\subsection{Local and systemic integration of nutrient signals}

The ability of root systems to sense and respond to local heterogeneity in the distribution of nutrients in the soil environment has been studied since the early work of Malcolm Drew (28), which showed a higher proliferation of roots in areas of soil with high concentrations of nitrate. These first experiments suggested a possible long-distance signalling mechanism at the whole-plant level to modulate local and root system-wide growth dynamics. In recent years, several discoveries have shown that nutrient transporters such as the nitrate transporter NRT1.1 can also function as sensors of their substrate, providing a possible mechanism for nutrient level-dependent regulation of root growth (73). At low nitrate concentrations, NTRT1.1 can also transport auxin and repress lateral root growth by enhancing basipetal transport of auxin out of the root tips $(67,13)$. Roots also synthesized small peptides like CEP1 (98) or the CLAVATA3/ESR-related small peptide, which is sensed locally by the leucine-rich repeat receptor kinase (LRR-RK) CLAVATA1 (1), and inhibits lateral root emergence (fig. 4).

How do root systems balance local signaling cues for nitrogen with whole-plant nutritional demands? Cytokinin has been shown to be involved partly in this so-called nitrogen economics (123). In addition, local nitrogen deprivation induces CEP1, which travels to the aerial part of the plant where it binds to at least two LRR-RKs (131). A yet to be discovered signalling molecule is then thought to mediate shoot to root communication that causes induction of root growth in parts of the root system with high nitrogen but not in nutrient deficient regions where local mechanisms primarily act to limit growth $(98,1,67)$. This regulatory system allows a fine modulation of root growth dynamics in soil patches with different nutrient concentrations $(131,11)$ (fig. 4).

Small RNA molecules constitute a molecular mechanism for long-distance signal transmission that directly affects gene expression $(64,63)$. Endogenous phosphorus levels are sensed in the aerial part, where phosphorus is needed to form phospholipids in the choloroplast membrane among other functions, by SPX1, a phosphate sensor that binds to PHR1 under high phosphorus levels but not under low levels $(112,141)$. Under low phosphorus levels, PHR1 upregulates the expression of several genes involved in the 


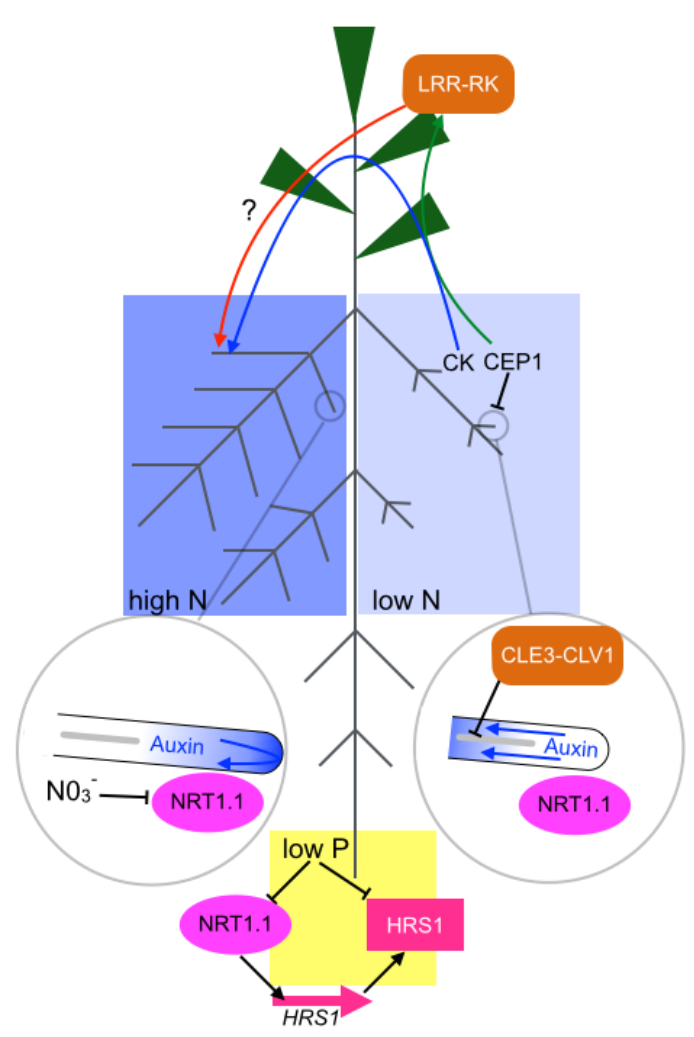

Figure 4

Diagrammatic view of local and long-distance signalling of heterogeneous distributions of nitrogen and its effects on root growth. Under low nitrogen, small peptides can repress root growth locally and also travel to the aerial part where they bind to LRR-RK that then trigger a long-distance signal that induces growth in high-nitrogen areas. Under low nitrogen, NRT1.1 can transport auxin basipetally and also reduce growth. Under low phosphorus conditions primary root growth is reduced, but only if sufficient concentrations of nitrogen are present. This process is regulated by HRS1.

phosphorus deficiency response including miR399. Grafting experiments using shoots overexpressing miR399 demonstrate the processed small RNA can move from shoots to roots, where it downregulates the expression of its target transcript PHO2 (105), an E2-conjugating ubiquitin enzyme that, under sufficient phosphorus conditions, facilitates the degradation of PHO1, the xylem phosphate loading transporter that also controls root system architecture $(4,120)$ and other phosphorus uptake transporters. This mechanism enables miRNA-mediated long distance communication of phosphorus levels in the shoot leading to modulation of phosphorus uptake mechanisms in the root. 


\subsection{Towards an understanding of how root systems integrate complex nutritional signals}

Most of the work done so far to understand the effects of different environmental cues such as salinity and nutrient deficiency were limited to controlled changes in a single environmental parameter, something that is far from what occurs in a natural soil environment. In the last years several studies have started to explore interactions between different environmental cues and how this is regulated at the transcriptional level to affect root system architecture. Nutrient crosstalk is, in part, explained by the chemical interactions that occur in the rhizosphere between the nutrients. For example, iron and phosphate form insoluble precipitates, not available to the plant, inducing the activation of both phosphorus and iron acquisition machinery. Thus, under low $\mathrm{P}, \mathrm{Fe}$ acquisition is upregulated and can lead to Fe toxicity, which suppresses primary root growth (142). PHR1, a master regulator of the $\mathrm{P}$ deficiency response, physically interacts with the AtFer 1 ferritin promoter and regulates its expression (14).

As mentioned earlier, differences in mobility of phosphorus and nitrogen in soil require distinct architectural responses (109). A recent report has provided evidence of the molecular crosstalk at the transcriptional and post-translational level between phosphorus and nitrogen (91). The authors discovered HRS1, a nitrate inducible, NRT1.1 controlled, transcription factor that, together with its homologue NIGT1, represses primary root growth under $\mathrm{P}$ deficiency but only if nitrate is available (91).

Changes induced by different nutritional levels in root system architecture have been systematically studied and root plasticity evaluated in terms of multivariate analysis of different traits, thus providing a framework to understand common effects of different nutrients (48). By using binary combinations of different nutrients and analysis of their effects on root system architecture traits, it was shown that transcriptionally coregulated clusters of nutrient-responsive genes in roots and ionome composition in leaves could be assigned to root architecture traits in Nitrogen/Phosphorus/Potassium binary combinations (65). The idea of using proxy traits such as shoot ion content as a readout of root system architecture or root function traits is of interest to root biologists and is already being explored with very promising results (69).

\section{Conclusions}

Studies of root biology bring with it challenges and opportunities to understand the intimate interaction between the plant and its environment. The biology of the shoot is also under tremendous pressures from the environment and many of the considerations when analyzing the multidimensional nature of roots will likely apply to the above ground organ systems as well. How an organism that lacks a centralized information processing center, such as the nervous system in metazoans, integrates environmental information across a vast physical network and coordinates responses is a grand challenge in plant biology and will likely reveal principles of organization that are different from animal models. In the case of plants, understanding such processes at a quantitative and predictive level may enable efficient control over plant growth for sustainable agriculture. 


\section{SUMMARY POINTS}

1. Soil physicochemical properties can vary at different spatio-temporal scales defining a very heterogeneous environment.

2. The complexity of soil-root interactions calls for the use of computer models, to help integrate the different processes.

3. Linking models with quantitative data remains challenging. The development of common formalisms for root system architecture characterisation will facilitate such integration.

4. Root systems are composed of different root types that perform specialized roles in root soil exploration. Root function and developmental programs enable acclimation to macro and micro-scale soil conditions.

5. Root systems use a variety of mechanism to adjust growth dynamics to local conditions such as patchy distributions of nutrients and water. These signals are integrated using different systemic signals at the whole plant and root system level to adjust root and plant growth accordingly.

\section{FUTURE ISSUES}

1. More research will be put in the study of perennial roots, that are interesting both from the perspective of basic biology (regeneration etc.) and can have a huge potential impact in agricultural practices.

2. Understanding how plants integrate signals from different nutrients at different concentrations and locations within the root system will require the development of new methods able to capture this complex interactions.

3. Transgenic approaches targeting specific root architecture and functionals traits like lateral root growth or exudate production could be deployed in the field to address specific challenges.

4. Field shoot application of silencing RNAs could be a good way to modulate root growth dynamics at specific plant developmental stages

\section{DISCLOSURE STATEMENT}

The authors are not aware of any affiliations, memberships, funding, or financial holdings that might be perceived as affecting the objectivity of this review.

\section{ACKNOWLEDGMENTS}

Rubén Rellán-Álvarez is supported by a Conacyt Ciencia Básica Young Investigator Grant (CB-2014-01-238101). Guillaume Lobet is supported by the Belgian Fond National de la Recherche Scientifique (1.B.237.15F). José R. Dinneny is supported by the Carnegie Institution for Science endowment and grants from the National Science Foundation (MCB1157895 and IOS-PGRP 420-40-45A) and from the Department of Energy, Biological and Environmental Research program (DE-SC0008769). The authors want to thank Gabriel 
Krouk, Craig Sturrock, Neil Robbins II, Heike Lindner, Jose Sebastian and Josep VilarrasaBlasi for critically reviewing the manuscript and helpful suggestions.

\section{LITERATURE CITED}

1. Araya T, Miyamoto M, Wibowo J, Suzuki A, Kojima S, et al. 2014. CLE-CLAVATA1 peptide-receptor signaling module regulates the expansion of plant root systems in a nitrogendependent manner. Proc. Natl. Acad. Sci. USA 111:2029-2034

2. Babé A, Lavigne T, Séverin JP, Nagel KA, Walter A, et al. 2012. Repression of early lateral root initiation events by transient water deficit in barley and maize. Philos. T. R. Soc. B 367:1534-1541

3. Bao Y, Aggarwal P, Robbins NE, Sturrock CJ, Thompson MC, et al. 2014. Plant roots use a patterning mechanism to position lateral root branches toward available water. Proc. Natl. Acad. Sci. USA 111:9319-9324

4. Bari R, Datt Pant B, Stitt M, Scheible WR. 2006. PHO2, microRNA399, and PHR1 define a phosphate-signaling pathway in plants. Plant Physiol. 141:988-999

5. Bateman RM, Crane PR, DiMichele WA, Kenrick PR, Rowe NP, et al. 1998. Early evolution of land plants: phylogeny, physiology, and ecology of the primary terrestrial radiation. Annu. Rev. Ecol. Evol. S. 29:263-292

6. Baxter I, Brazelton JN, Yu D, Huang YS, Lahner B, et al. 2010. A coastal cline in sodium accumulation in Arabidopsis thaliana is driven by natural variation of the sodium transporter AtHKT1;1. PLoS Genet 6:e1001193

7. Bayuelo-Jiménez JS, Gallardo-Valdéz M, Pérez-Decelis VA, Magdaleno-Armas L, Ochoa I, Lynch JP. 2011. Genotypic variation for root traits of maize (Zea maysL.) from the Purhepecha Plateau under contrasting phosphorus availability. Field Crops Research 121:350-362

8. Benfey PN. 2012. Toward a systems analysis of the root. Cold Spring Harbor symposia on quantitative biology 77:91-6

9. Bennett MJ, Marchant A, Green HG, May ST, Ward SP, et al. 1996. Arabidopsis AUX1 gene: A permease-like regulator of root gravitropism. Science 273:948-950

10. Berner RA. 1997. Geochemistry and geophysics: the rise of plants and their effect on weathering and atmospheric co2. Science 276:544-546

11. Bisseling T, Scheres B. 2014. Nutrient computation for root architecture. Science 346:300-301

12. Bodner G, Leitner D, Nakhforoosh A, Sobotik M, Moder K, Kaul HP. 2013. A statistical approach to root system classification. Front. Plant Sci. 4

13. Bouguyon E, Brun F, Meynard D, Kubeš M, Pervent M. 2015. Multiple mechanisms of nitrate sensing by Arabidopsis nitrate transceptor NRT1. 1. Nature Plants

14. Bournier M, Tissot N, Mari S, Boucherez J, Lacombe E, et al. 2013. Arabidopsis ferritin 1 (AtFer1) gene regulation by the phosphate starvation response 1 (AtPHR1) transcription factor reveals a direct molecular link between iron and phosphate homeostasis. J. Biol. Chem. 288:22670-22680

15. Brady NC, Weil RR. 2008. The nature and properties of soils. Upper Saddle River, New Jersey: Pearson- Prentice Hall, revised 14 ed.

16. Brady SM, Orlando DA, Lee JY, Wang JY, Koch J, et al. 2007. A high-resolution root spatiotemporal map reveals dominant expression patterns. Science 318:801-806

17. Busoms S, Teres J, Huang X, Bomblies K, Danku J, et al. 2015. Salinity is an agent of divergent selection driving local adaptation of Arabidopsis thaliana to coastal habitats. Plant Physiol. 168:915-29

18. Cai J, Zeng Z, Connor JN, Huang CY, Melino V, et al. 2015. RootGraph: a graphic optimization tool for automated image analysis of plant roots. J. Exp. Bot.

19. Caldwell MM, Richards JH. 1989. Hydraulic lift: water efflux from upper roots improves effectiveness of water uptake by deep roots. Oecologia 79:1-5 
20. Chen YL, Dunbabin VM, Postma JA, Diggle AJ, Siddique KHM, Rengel Z. 2013. Modelling root plasticity and response of narrow-leafed lupin to heterogeneous phosphorus supply. Plant Soil 372:319-337

21. Chitwood DH, Topp CN. 2015. Revealing plant cryptotypes: defining meaningful phenotypes among infinite traits. Curr. Opin. Plant Biol. 24:54-60

22. Digby J, Firn RD. 1995. The gravitropic set-point angle (GSA): the identification of an important developmentally controlled variable governing plant architecture. Plant Cell Environ. 18:1434-1440

23. Dinneny JR. 2014. A gateway with a guard: how the endodermis regulates growth through hormone signaling. Plant Sci. 214:14-19

24. Dinneny JR, Long TA, Wang JY, Jung JW, Mace D, et al. 2008. Cell identity mediates the response of Arabidopsis roots to abiotic stress. Science 320:942-945

25. Doebley J, Stec A, Gustus C. 1995. Teosinte branched1 and the origin of maize: evidence for epistasis and the evolution of dominance. Genetics 141:333-346

26. Downie H, Holden N, Otten W, Spiers AJ, Valentine TA, Dupuy L. 2012. Transparent soil for imaging the rhizosphere. PLoS ONE 7:1-6

27. Draye X, Kim Y, Lobet G, Javaux M. 2010. Model-assisted integration of physiological and environmental constraints affecting the dynamic and spatial patterns of root water uptake from soils. J. Exp. Bot. 61:2145-2155

28. Drew M. 1975. Comparison of the effects of a localised supply of phosphate, nitrate, ammonium and potassium on the growth of the seminal root system, and the shoot, in barley. New Phytol. :479-490

29. Duan L, Dietrich D, Ng CH, Chan PMY, Bhalerao R, et al. 2013. Endodermal ABA signaling promotes lateral root quiescence during salt stress in arabidopsis seedlings. Plant Cell 25:324341

30. Dunbabin VM, Postma JA, Schnepf A, Pagès L, Javaux M, et al. 2013. Modelling root-soil interactions using three-dimensional models of root growth, architecture and function. Plant Soil 372:93-124

31. Dupuy L, Fourcaud T, Stokes A, Danjon F. 2005. A density-based approach for the modelling of root architecture: application to Maritime pine (Pinus pinaster Ait.) root systems. J. Theor. Biol. 236:323-334

32. Dupuy L, Gregory PJ, Bengough AG. 2010. Root growth models: towards a new generation of continuous approaches. J. Exp. Bot. 61:2131-2143

33. Dupuy L, Vignes M, McKensie BM, White PJ. 2010. The dynamics of root meristem distribution in the soil. Plant Cell Envi. 33:358-369

34. Durrett TP, Gassmann W, Rogers EE. 2007. The FRD3-mediated efflux of citrate into the root vasculature is necessary for efficient iron translocation. Plant Physiol. 144:197-205

35. Eshel A, Waisel Y. 1996. In Plant Roots: The Hidden Half, eds. Y Waisel, A Eshel, U Kafkafi. Marcel Dekker, Inc, 175-192

36. Fang S, Clark RT, Zheng Y, Iyer-Pascuzzi AS, Weitz JS, et al. 2013. Genotypic recognition and spatial responses by rice roots. Proc. Natl. Acad. Sci. USA 110:2670-2675

37. Fitter AH. 1987. An architectural approach to the comparative ecology of plant root systems. New Phytol. 106:61-77

38. Fitter AH, Stickland TR, Harvey ML, Wilson GW. 1991. Architectural analysis of plant root systems 1. Architectural correlates of exploitation efficiency. New Phytol. 118:375-382

39. Flowers T, Yeo A. 1995. Breeding for salinity resistance in crop plants: where next? Aust. J. Plant Physiol. 22:875

40. Furbank RT, Tester M. 2011. Phenomics - technologies to relieve the phenotyping bottleneck. Trends Plant Sci. 16:635-644

41. Galkovskyi T, Mileyko Y, Bucksch A, Moore B, Symonova O, et al. 2012. GiA Roots: software for the high throughput analysis of plant root system architecture. BMC Plant Biol. 12:116 
42. Gaudin ACM, McClymont SA, Soliman SSM, Raizada MN. 2014. The effect of altered dosage of a mutant allele of Teosinte branched 1 (tb1) on the root system of modern maize. BMC Gen. 15:23

43. Ge Z, Rubio G, Lynch JP. 2000. The importance of root gravitropism for inter-root competition and phosphorus acquisition efficiency: results from a geometric simulation model. Plant Soil 218:159-171

44. Geldner N. 2013. The endodermis. Annu. Rev. Plant Biol.

45. Geng Y, Wu R, Wee CW, Xie F, Wei X, et al. 2013. A spatio-temporal understanding of growth regulation during the salt stress response in Arabidopsis. The Plant Cell . . 25:2132-2154

46. Giehl R, von Wirén N. 2014. Root nutrient foraging. Plant Physiol.

47. Godin C, Sinoquet H. 2005. Functional-structural plant modelling. New Phytol. 166:705-708

48. Gruber BD, Giehl RFH, Friedel S, von Wirén N. 2013. Plasticity of the Arabidopsis root system under nutrient deficiencies. Plant Physiol. 163:161-179

49. Hackett C, Rose DA. 1972. A model of the extension and branching of a seminal root of barley, and its use in studying relations between root dimensions. I. The model. Aust. J. Biol. Sci. 25:681-690

50. Hamburger D, Rezzonico E, MacDonald-Comber Petétot J, Somerville C, Poirier Y. 2002. Identification and characterization of the Arabidopsis PHO1 gene involved in phosphate loading to the xylem. Plant Cell 14:889-902

51. Heppell J, Talboys P, Payvandi S, Zygalakis KC, Fliege J, et al. 2014. How changing root system architecture can help tackle a reduction in soil phosphate $(\mathrm{P})$ levels for better plant $\mathrm{P}$ acquisition. Plant Cell Environ. 38:118-128

52. Ho MD, B, McCannon C, Lynch JP. 2004. Optimization modeling of plant root architecture for water and phosphorus acquisition. Journal of Theoretical Botany 226:331-340

53. Hochholdinger F. 2009. In Handbook of Maize: Its biology. New York, NY: Springer New York, 145-160

54. Hohmann-Marriott MF, Blankenship RE. 2011. Evolution of photosynthesis. Annu. Rev. Plant Biol. 62:515-48

55. Huber K, Vanderborght J, Javaux M, Schröder N, Dodd IC, Vereecken H. 2014. Modelling the impact of heterogeneous rootzone water distribution on the regulation of transpiration by hormone transport and/or hydraulic pressures. Plant Soil 184

56. Jackson RB, Sperry JS, Dawson TE. 2000. Root water uptake and transport: using physiological processes in global predictions. Trends Plant Sci. 5:482-488

57. Jaramillo RE, Nord EA, Chimungu JG, Brown KM, Lynch JP. 2013. Root cortical burden influences drought tolerance in maize. Ann. Bot. 112:429-437

58. Jarvis PG. 1976. The interpretation of the variations in leaf water potential and stomatal conductance found in canopies in the field. Philos. T. R. Soc. B 273:593-610

59. Javaux M, Schroeder T, Vanderborght J, Vereecken H. 2008. Use of a three-dimensional detailed modeling approach for predicting root water uptake. . Vadose Zone Journal 7:1079-1088

60. Jones VAS, Dolan L. 2012. The evolution of root hairs and rhizoids. Ann. Bot. 110:205-12

61. Julkowska MM, Hoefsloot HCJ, Mol S, Feron R, de Boer GJ, et al. 2014. Capturing Arabidopsis root architecture dynamics with ROOT-FIT reveals diversity in responses to salinity. Plant Physiol. 166:1387-1402

62. Karahara I, Ikeda A, Kondo T, Uetake Y. 2004. Development of the Casparian strip in primary roots of maize under salt stress. Planta 219:41-47

63. Kehr J. 2013. Systemic regulation of mineral homeostasis by micro RNAs. Front. Plant Sci. 4:145

64. Kehr J, Buhtz A. 2008. Long distance transport and movement of RNA through the phloem. J. Exp. Bot. 59:85-92

65. Kellermeier F, Armengaud P, Seditas TJ, Danku J, Salt DE, Amtmann A. 2014. Analysis of the root system architecture of arabidopsis provides a quantitative readout of crosstalk 
between nutritional signals. Plant Cell 26:1480-1496

66. Knee EM, Gong FC, Gao M, Teplitski M, Jones AR, et al. 2001. Root mucilage from pea and its utilization by rhizosphere bacteria as a sole carbon source. Mol. Plant Microbe In. 14:775-84

67. Krouk G, Lacombe B, Bielach A, Perrine-Walker F, Malinska K, et al. 2010. Nitrate-regulated auxin transport by NRT1.1 defines a mechanism for nutrient sensing in plants. Dev. Vell 18:927-937

68. Lambers H, Finnegan PM, Jost R, Plaxton WC, Shane MW, Stitt M. 2015. Phosphorus nutrition in Proteaceae and beyond. Nature Plants 1:15109

69. Lambers H, Hayes PE, Laliberté E, Oliveira RS. 2015. Leaf manganese accumulation and phosphorus-acquisition efficiency. Trends Plant Sci. 20:83-90

70. Larry M York EANJPL. 2013. Integration of root phenes for soil resource acquisition. Front. Plant Sci. 4:355

71. Le Marié C, Kirchgessner N, Marschall D, Walter A, Hund A. 2014. Rhizoslides: paperbased growth system for non-destructive, high throughput phenotyping of root development by means of image analysis. Plant Methods 10:13

72. Leitner D, Klepsch S, Bodner G, Schnepf A. 2010. A dynamic root system growth model based on L-Systems. Plant Soil 332:117-192

73. Liu KH, Tsay YF. 2003. Switching between the two action modes of the dual-affinity nitrate transporter CHL1 by phosphorylation. EMBO J 22:1005-1013

74. Lobet G, Draye X. 2013. Novel scanning procedure enabling the vectorization of entire rhizotron-grown root systems. Plant Methods 9:2-10

75. Lobet G, Pagès L, Draye X. 2014. A modeling approach to determine the importance of dynamic regulation of plant hydraulic conductivities on the water uptake dynamics in the soil-plant. Ecol. Model. 290:65-75

76. Lobet G, Pound MP, Diener J, Pradal C, Draye X, et al. 2015. Root System Markup Language: Toward a unified root architecture description language. Plant Physiol. 167:617-627

77. López-Arredondo DL, Leyva-González MA, González-Morales SI, López-Bucio J, HerreraEstrella L. 2014. Phosphate nutrition: improving low-phosphate tolerance in crops. Annu. Rev. Plant Biol. 65:95-123

78. Lowry DB, Hall MC, Salt DE, Willis JH. 2009. Genetic and physiological basis of adaptive salt tolerance divergence between coastal and inland Mimulus guttatus. New Phytol. 183:776-788

79. Lungley DR. 1973. The growth of root systems - A numerical computer simulation model. Plant Soil 38:145-159

80. Lynch JP. 2011. Root phenes for enhanced soil exploration and phosphorus acquisition: tools for future crops. Plant Physiol. 156:1041-1049

81. Lynch JP. 2013. Steep, cheap and deep: an ideotype to optimize water and N acquisition by maize root systems. Ann. Bot. 112:347-357

82. Lynch JP, Brown KM. 2012. New roots for agriculture: exploiting the root phenome. Philos. T. R. Soc. B 367:1598-1604

83. Lynch JP, Nielsen KL, Davis RD, Jablokow AG. 1997. SimRoot: Modelling and visualization of root systems. Plant Soil 188:139-151

84. Lynch JP, Wojciechowski T. 2015. Opportunities and challenges in the subsoil: pathways to deeper rooted crops. J. Exp. Bot. 66:2199-2210

85. Mahner M, Kary M. 1997. What exactly are genomes, genotypes and phenotypes? And what about phenomes? Journal of Theoretical Biology 186:55-63

86. Mairhofer S, Zappala S, Tracy S, Sturrock C, Bennett M, et al. 2011. RooTrak: Automated recovery of 3D plant root architecture in soil from X-ray Micro Computed Tomography using visual tracking. Plant Physiol. 158:561-569

87. Marschner P. 2012. Marschner's mineral nutrition of higher plants. Academic Press

88. Mathieu L, Lobet G, Tocquin P, Périlleux C. 2015. Rhizoponics: a novel hydroponic rhizotron 
for root system analyses on mature Arabidopsis thaliana plants. Plant Methods 11:1-7

89. McCully ME. 1999. Roots in soil: unearthing the complexities of roots and their rhizospheres. Annu. Rev. Plant Phys. Plant Mol. Biol. 50:695-718

90. McCully ME, Canny MJ. 1988. Pathways and processes of water and nutrient movement in roots. Plant Soil 111:159-170

91. Medici A, Marshall-Colon A, Ronzier E, Szponarski W, Wang R, et al. 2015. AtNIGT1/HRS1 integrates nitrate and phosphate signals at the Arabidopsis root tip. Nature Comm. 6:6274

92. Metzner R, Eggert A, van Dusschoten D, Pflugfelder D, Gerth S, et al. 2015. Direct comparison of MRI and X-ray CT technologies for 3D imaging of root systems in soil: potential and challenges for root trait quantification. Plant Methods 11:17

93. Miguel MA, Postma JA, Lynch JP. 2015. Phene synergism between root hair length and basal root growth angle for phosphorus acquisition. Plant Physiol. 167:1430-1439

94. Moreno-Risueno MA, Van Norman JM, Moreno A, Zhang J, Ahnert SE, Benfey PN. 2010. Oscillating gene expression determies competence for periodic Arabidopsis root branching. Science 329:1306-1311

95. Moriwaki T, Miyazawa Y, Kobayashi A, Takahashi H. 2013. Molecular mechanisms of hydrotropism in seedling roots of Arabidopsis thaliana (Brassicaceae). Am. J. Bot. 100:25-34

96. North GB, Nobel PS. 1997. Drought-induced changes in soil contact and hydraulic conductivity for roots of Opuntia ficus-indica with and without rhizosheaths. Plant Soil 191:249-258

97. Oades J. 1993. The role of biology in the formation, stabilization and degradation of soil structure. Geoderma 56:377-400

98. Ohyama K, Ogawa M, Matsubayashi Y. 2008. Identification of a biologically active, small, secreted peptide in Arabidopsis by in silico gene screening, followed by LC-MS-based structure analysis. Plant J. 55:152-160

99. Oldroyd GED, Murray JD, Poole PS, Downie JA. 2011. The rules of engagement in the legume-rhizobial symbiosis. Annu. Rev. Genet. 45:119-144

100. Orman-Ligeza B, Parizot B, Gantet PP, Beeckman T, Bennett MJ, Draye X. 2013. Postembryonic root organogenesis in cereals: branching out from model plants. Trends Plant Sci. 18:459-467

101. Osmont KS, Sibout R, Hardtke CS. 2007. Hidden branches: developments in root system architecture. Annu. Rev. Plant Biol. 58:93-113

102. Pacheco-Villalobos D, Hardtke CS. 2012. Natural genetic variation of root system architecture from Arabidopsis to Brachypodium: towards adaptive value. Philosophical Transactions of the Royal Society of London B: Biological Sciences 367:1552-1558

103. Pagès L, Bécel C, Boukcim H, Moreau D, Nguyen C, Voisin AS. 2013. Calibration and evaluation of ArchiSimple, a simple model of root system architecture. Ecol. Model. 290:76-84

104. Pagès L, Vercambre G, Drouet JL, Lecompte F, Collet C, LeBot J. 2004. RootTyp: a generic model to depict and analyse the root system architecture. Plant Soil 258:103-119

105. Pant BD, Buhtz A, Kehr J, Scheible WR. 2008. MicroRNA399 is a long-distance signal for the regulation of plant phosphate homeostasis. Plant J. 53:731-738

106. Peng Y, Li X, Li C. 2012. Temporal and spatial profiling of root growth revealed novel response of maize roots under various nitrogen supplies in the field. PLOS ONE 7:e37726

107. Pérez-Torres CA, López-Bucio J, Cruz-Ramirez A, Ibarra-Laclette E, Dharmasiri S, et al. 2008. Phosphate availability alters lateral root development in Arabidopsis by modulating auxin sensitivity via a mechanism involving the TIR1 auxin receptor. Plant Cell 20:3258-3272

108. Pfister A, Barberon M, Alassimone J, Kalmbach L, Lee Y, et al. 2014. A receptor-like kinase mutant with absent endodermal diffusion barrier displays selective nutrient homeostasis defects. eLife 3:e03115

109. Postma JA, Dathe A, Lynch JP. 2014. The optimal lateral root branching density for maize depends on nitrogen and phosphorus availability. Plant Physiol. 166:590-602

110. Postma JA, Lynch JP. 2011. Root cortical aerenchyma enhances the growth of maize on soils 
with suboptimal availability of nitrogen, phosphorus, and potassium. Plant Physiol. 156:11901201

111. Postma JA, Lynch JP. 2011. Theoretical evidence for the functional benefit of root cortical aerenchyma in soils with low phosphorus availability. Ann. Bot. 107:829-841

112. Puga MI, Mateos I, Charukesi R, Wang Z, Franco-Zorrilla JM, et al. 2014. SPX1 is a phosphatedependent inhibitor of Phosphate Starvation Response 1 in Arabidopsis. Proc. Natl. Acad. Sci. USA 111:14947-14952

113. Rasse DP, Rumpel C, Dignac MF. 2005. Is soil carbon mostly root carbon? Mechanisms for a specific stabilisation. Plant Soil 269:341-356

114. Rellán-Álvarez R, Giner-Martinez-Sierra J, Orduna J, Orera I, Rodríguez-Castrillón JÁ, et al. 2010. Identification of a tri-iron(iii), tri-citrate complex in the xylem sap of iron-deficient tomato resupplied with iron: new insights into plant iron long-distance transport. Plant Cell Physiol. 51:91-102

115. Rellán-Álvarez R, Lobet G, Lindner H, Pradier PL, Sebastian J, et al. 2015. GLO-Roots: an imaging platform enabling multidimensional characterization of soil-grown root systems. eLife 4:e07597

116. Retallack GJ. 1997. Early forest soils and their role in devonian global change. Science 276:583585

117. Robbins NE, Dinneny JR. 2015. The divining root: moisture-driven responses of roots at the micro- and macro-scale. J. Exp. Bot. 66:2145-2154

118. Robbins NE, Trontin C, Duan L, Dinneny JR. 2014. Beyond the barrier: communication in the root through the endodermis. Plant Physiol. 166:551-559

119. Ron M, Dorrity MW, de Lucas M, Toal T, Hernandez RI, et al. 2013. Identification of novel loci regulating interspecific variation in root morphology and cellular development in tomato. Plant Physiol. 162:755-768

120. Rosas U, Cibrian-Jaramillo A, Ristova D, Banta JA, Gifford ML, et al. 2013. Integration of responses within and across Arabidopsis natural accessions uncovers loci controlling root systems architecture. Proc. Natl. Acad. Sci. USA 110:15133-15138

121. Rosquete MR, von Wangenheim D, Marhavý P, Barbez E, Stelzer EHK, et al. 2013. An auxin transport mechanism restricts positive orthogravitropism in lateral roots. Curr. Biol. 23:817822

122. Rost TL. 2011. The organization of roots of dicotyledonous plants and the positions of control points. Ann. Bot. 107:1213-1222

123. Ruffel S, Krouk G, Ristova D, Shasha D, Birnbaum KD, Coruzzi GM. 2011. Nitrogen economics of root foraging: transitive closure of the nitrate-cytokinin relay and distinct systemic signaling for N supply vs. demand. Proc. Natl. Acad. Sci. USA 108:18524-18529

124. Saengwilai P, Nord EA, Chimungu JG, Brown KM, Lynch JP. 2014. Root cortical aerenchyma enhances nitrogen acquisition from low-nitrogen soils in maize. Plant Physiol. 166:726-735

125. Schroeder N, Lazarovitch N, Vanderborght J, Vereecken H, Javaux M. 2013. Linking transpiration reduction to rhizosphere salinity using a 3D coupled soil-plant model. Plant Soil 377

126. Sieber T, Grunig C. 2013. In Plant Roots: The Hidden Half, eds. A Eshel, T Beeckman. New york: CRC Press, 38-49

127. Šimůnek J, Hopmans JW. 2009. Modeling compensated root water and nutrient uptake. Ecol. Model. 220:505-521

128. Singh P, Mohanta TK, Sinha AK. 2015. Unraveling the intricate nexus of molecular mechanisms governing rice root development: OsMPK3/6 and auxin-cytokinin interplay. PLoS ONE 10:e0123620

129. Svistoonoff S, Creff A, Reymond M, Sigoillot-Claude C, Ricaud L, et al. 2007. Root tip contact with low-phosphate media reprograms plant root architecture. Nature Genetics 39:792-796

130. Symonova O, Topp CN, Edelsbrunner H. 2015. DynamicRoots: A software platform for the 
reconstruction and analysis of growing plant roots. PLoS ONE 10:e0127657-15

131. Tabata R, Sumida K, Yoshii T, Ohyama K, Shinohara H, Matsubayashi Y. 2014. Perception of root-derived peptides by shoot LRR-RKs mediates systemic N-demand signaling. Science 346:343-346

132. Tian H, De Smet I, Ding Z. 2014. Shaping a root system: regulating lateral versus primary root growth. Trends Plant Sci. 19:426-431

133. Topp CN, Iyer-Pascuzzi AS, Anderson JT, Lee CR, Zurek PR, et al. 2013. 3D phenotyping and quantitative trait locus mapping identify core regions of the rice genome controlling root architecture. Proc. Natl. Acad. Sci. USA 110:E1695-704

134. Tracy SR, Black CR, Roberts JA, Sturrock C, Mairhofer S, et al. 2012. Quantifying the impact of soil compaction on root system architecture in tomato (Solanum lycopersicum) by X-ray micro-computed tomography. Ann. Bot. 110:511-9

135. Tracy SR, Daly KR, Sturrock CJ, Crout NMJ, Mooney SJ, Roose T. 2015. Three-dimensional quantification of soil hydraulic properties using X-ray Computed Tomography and image-based modeling. Water Resour. Res. 51:1006-1022

136. Tyree MT, Sperry JS. 1989. Vulnerability of xylem to cavitation and embolism. Annual Review of Plant Physiology and Plant Molecular Biology 40:19-36

137. Uga Y, Sugimoto K, Ogawa S, Rane J, Ishitani M, et al. 2013. Control of root system architecture by DEEPER ROOTING 1 increases rice yield under drought conditions. Nature Gen. 45:1097-1102

138. Van Norman JM, Xuan W, Beeckman T, Benfey PN. 2013. To branch or not to branch: the role of pre-patterning in lateral root formation. Development 140:4301-4310

139. Verslues PE, Agarwal M, Katiyar-Agarwal S, Zhu J, Zhu JK. 2006. Methods and concepts in quantifying resistance to drought, salt and freezing, abiotic stresses that affect plant water status. Plant J. 45:523-539

140. Walker TS, Bais HP, Grotewold E, Vivanco JM. 2003. Root exudation and rhizosphere biology. Plant Physiol. 132:44-51

141. Wang Z, Ruan W, Shi J, Zhang L, Xiang D, et al. 2014. Rice SPX1 and SPX2 inhibit phosphate starvation responses through interacting with PHR2 in a phosphate-dependent manner. Proc. Natl. Acad. Sci. USA 111:14953-14958

142. Ward JT, Lahner B, Yakubova E, Salt DE, Raghothama KG. 2008. The effect of iron on the primary root elongation of Arabidopsis during phosphate deficiency. Plant Physiol. 147:11811191

143. Watt M, McCully M, Canny M. 1994. Formation and stabilization of rhizosheaths of Zea mays L. Plant Physiol. 106:179-186

144. Yan F, Zhu Y, Müller C, Zörb C, Schubert S. 2002. Adaptation of H+-pumping and plasma membrane $\mathrm{H}+$ ATPase activity in proteoid roots of white lupin under phosphate deficiency. Plant Physiol. 129:50-63

145. York LM, Nord EA, Lynch JP. 2013. Integration of root phenes for soil resource acquisition Front. Funct. Plant Ecol. :1-35

146. Yu J, Li Y, Han G, Zhou D, Fu Y, et al. 2013. The spatial distribution characteristics of soil salinity in coastal zone of the Yellow River Delta. Envi. Earth Sci. 72:589-599

147. Zurek PR, Topp CN, Benfey PN. 2015. Quantitative Trait Locus mapping reveals regions of the maize genome controlling root system architecture. Plant Physiol. 167:1487-1496 